\title{
Association between MDM2 SNP309 T>G polymorphism and the risk of bladder cancer: new data in a Chinese population and an updated meta-analysis
}

\author{
This article was published in the following Dove Press journal: \\ OncoTargets and Therapy \\ 7 December 2015 \\ Number of times this article has been viewed
}

\author{
Linguo $\mathrm{Xie}^{1,2, *}$ \\ Yan Sun ${ }^{2, *}$ \\ Tao Chen ${ }^{1,2, *}$ \\ Dawei Tian ${ }^{1,2}$ \\ Yujuan $\mathrm{Li}^{3}$ \\ Yu Zhang ${ }^{1,2}$ \\ $\mathrm{Na}$ Ding $^{2}$ \\ Zhonghua Shen ${ }^{1,2}$ \\ Hao $X u^{1,2}$ \\ Xuewu Nian ${ }^{4}$ \\ Nan Sha ${ }^{1,2}$ \\ Ruifa Han ${ }^{1,2}$ \\ Hailong $\mathrm{Hu}^{1,2}$ \\ Changli $\mathrm{Wu}^{1,2}$ \\ 'Department of Urology, The \\ Second Hospital of Tianjin Medical \\ University, ${ }^{2}$ Tianjin Key Laboratory of \\ Urology, Tianjin Institute of Urology, \\ ${ }^{3}$ Department of Dermatology, The \\ Second Hospital of Tianjin Medical \\ University, ${ }^{4}$ Department of Urology, \\ Tianjin Nankai Hospital, Tianjin, \\ People's Republic of China \\ *These authors contributed equally \\ to this work
}

Correspondence: Hailong Hu; Changli Wu

Department of Urology, The Second Hospital of Tianjin Medical University, 23 Pingjiang Road, Hexi District, Tianjin 3002 II, People's Republic of China

Tel +86 22282732 II

Fax +86 22282732 II

Email hhllove2004@I63.com;

wujygc2003@163.com
Objective: Human murine double minute 2 protein (MDM2) is mainly a negative regulator of p53 tumor suppressor pathway. We aimed to investigate the association between MDM2 SNP309 polymorphism and bladder cancer risk.

Methods: A total of 535 bladder cancer patients and 649 health controls were recruited for our study. MDM2 SNP309 T > G polymorphism was genotyped by polymerase chain reaction-ligase detection reaction method. Logistic regression was used to analyze the relationship between the genotype and susceptibility of bladder cancer. Kaplan-Meier estimates and log-rank test were obtained to analyze the association between the genotype and risk of recrudesce in nonmuscleinvasive bladder cancer patients. A multivariable Cox proportional hazards model was fitted to identify independent prognostic factors. To further investigate the association, we conducted a meta-analysis including six studies.

Results: The frequency of the MDM2 SNP309 T $>$ G polymorphism showed no significant difference between cases and controls (all $P>0.05$ ). In the stratification analysis, the results showed that $\mathrm{G}$ allele carriers were prone to have a significant decrease in risk of low-grade bladder cancer (adjusted odds ratio: $0.613,95 \%$ confidence interval: $0.427-0.881$ ), and $\mathrm{G}$ variant was associated with a significantly reduced risk of recurrence in nonmuscle-invasive bladder cancer patients with or without chemotherapy $(P<0.05)$. The results of the meta-analysis showed that $G$ allele and GG genotype of MDM2 SNP309 polymorphism were significantly associated with increased risk of bladder cancer in Caucasians (both $P<0.05$ ), and no association was observed in total populations and Asians $(P>0.05)$.

Conclusion: MDM2 SNP309 T $>$ G polymorphism has no influence on bladder cancer risk in Asians, but this single nucleotide polymorphism may be associated with genetic susceptibility of bladder cancer among Caucasians.

Keywords: bladder cancer, MDM2, single nucleotide polymorphism, rs2279744, recurrence, meta-analysis

\section{Introduction}

Bladder cancer has become a significant threat to the public health, with a high incidence rate of 9.5/100,000 and 3.3/100,000 in the more developed and less developed region, respectively. ${ }^{1}$ According to the data provided by the International Agency for Research on Cancer, an estimated 429,800 new cases of bladder cancer and 165,100 deaths occurred in 2012 worldwide. ${ }^{1,2}$ For the population in the People's Republic of China, 55,486 new cases and 26,820 deaths were estimated in 2012, which indicate that bladder cancer is the 15 th most commonly diagnosed cancer and the 17 th leading 
cause of cancer deaths in the People's Republic of China. ${ }^{1}$ The majority of bladder cancer occurs in men, and men are about three to four times more likely to be diagnosed with this disease than women. ${ }^{3}$ Histological types of bladder cancer include transitional cell carcinoma, adenocarcinoma, squamous cell carcinoma, and other rare types, and more than $95 \%$ of bladder cancers are transitional cell carcinomas. ${ }^{4}$

Smoking tobacco has been established as the strongest risk factor for bladder cancer, and a meta-analysis demonstrated that smoking is associated with a threefold increase in risk for cancer of the lower urinary tract. ${ }^{5,6}$ Other suspected risk factors for bladder cancer include infections with Schistosoma haematobium, occupational exposure to chemical carcinogens, dietary patterns, and environmental pollution. ${ }^{7}$ Although numerous individuals are exposed to these risk factors, only a proportion will ever develop bladder cancer, indicating that genetic susceptibility is also a suspected risk factor for developing bladder cancer. Meanwhile, studies have found that people with family history of bladder cancer are associated with nearly twofold increased risk of developing bladder cancer, which also suggests that genetic susceptibility plays an important role in bladder carcinogenesis. ${ }^{8,9}$

The p53 tumor suppressor pathway has been shown to be crucial for the prevention of tumor formation. ${ }^{10}$ Somatic mutations that inactivate the p53 gene have been found in at least half of all human solid tumors, including bladder cancer. ${ }^{11}$ The human murine double minute 2 protein (MDM2) is a major negative regulator of p53 network, and overexpression of MDM2 can lead to the inactivation of the p53 pathway, diminishing its tumor suppressor function. ${ }^{12,13}$ The human MDM2 gene is located on chromosome 12q14.3q15, with a genomic length of $34 \mathrm{~kb} .{ }^{14}$ A single nucleotide polymorphism SNP309 (rs2279744, T>G) located in the promoter region of the MDM2 gene has been reported to be a risk factor in several cancers. ${ }^{15}$ The G allele of MDM2 SNP309 polymorphism showed a higher binding affinity to the transcription factor $\mathrm{Sp} 1$ than the T allele, which results in higher levels of MDM2 mRNA and protein in the individuals with $\mathrm{G}$ allele, and thereby inhibits the function of p53 pathway in prevention of tumor formation. ${ }^{10}$

There have been a number of studies reporting the association between MDM2 SNP309 polymorphism and bladder cancer risk, but the results were controversial and ambiguous. Therefore, we carried out a case-control study to evaluate the role of MDM2 SNP309 polymorphism in bladder cancer in the People's Republic of China. Moreover, an updated meta-analysis was performed to explore more precisely the association between MDM2 SNP309 polymorphism and bladder cancer risk.

\section{Materials and methods Study subjects}

A total of 535 patients newly diagnosed with histologically confirmed transitional cell carcinoma of bladder and 649 sexand age-matched cancer-free control subjects were enrolled in our case-control study, and all participants were recruited from The Second Hospital of Tianjin Medical University between May 2012 and June 2014. The patients with previous history of cancer, metastasized cancer from other or unknown origins, and those who underwent previous radiotherapy or chemotherapy were excluded. Control subjects were selected who were genetically unrelated to the cases, and had no evidence of malignancy or chronic disease. Control subjects were recruited from individuals seeking health care at the hospital and hospital employees. All included participants were of Chinese Han descent. The epidemiologic and demographic data were collected by interviewing each individual in cases and controls, and at the same time, informed consent was signed by all subjects. According to the criteria of the US Centers for Disease Control and Prevention, ${ }^{16}$ we stratified the patients into never smokers (who never smoked cigarettes or smoked fewer than 100 cigarettes in their entire life), former smokers (who smoked at least 100 cigarettes in their entire life but were not currently smoking), and current smokers (who had smoked at least 100 cigarettes in their entire life and were still smoking). A $4 \mathrm{~mL}$ peripheral venous blood sample was drawn into coded tubes after the interview. The present study was approved by the medical ethics committee of The Second Hospital of Tianjin Medical University.

\section{Clinical data collection}

The clinical information about tumor was obtained from medical record of the patients, in collaboration with urologists. Tumors were staged according to 2002 International Union Against Cancer tumor-nodes-metastasis classification and graded histologically according to the World Health Organization/International Society of Urological Pathology 2004 grading of urothelial papilloma. Tumor stage and grade was reevaluated by single group of pathologists in the Department of Pathology in our institute. Tumor grades stratification refers to either high grade or low grade, and papillary urothelial neoplasm of low malignant potential was classified as low grade in our study. ${ }^{17}$ The patients with muscle-invasive bladder cancer (MIBC) were treated with radical cystectomy with or without cisplatin-based adjuvant chemotherapy. 
In addition, the patients with nonmuscle-invasive bladder cancer (NMIBC) were treated with transurethral resection of bladder cancer combining with formal bladder instillation of drug. Partial patients with NMIBC of high grade received cisplatin-based combination chemotherapy for a maximum of six cycles unless progression or unacceptable toxicity appeared. All patients with NMIBC had regular cystoscopy every 3 months in first and second years after operation and later every 6 months as long as there was no tumor recurrence. There were two end points in our study, including tumor recurrence and the end of study time ( 24 months). The mean follow-up was $14.38 \pm 6.48$ months (3-24 months).

\section{DNA extraction and genotyping}

Genomic DNA was isolated from venous blood samples using a DNA extraction kit (Blood Genomic DNA Extraction Kit; Generay Biotech, Shanghai, People's Republic of China) according to the manufacturer's instructions. The MDM2 SNP309 T $>$ G polymorphism was genotyped by the polymerase chain reaction-ligation detection reaction (PCRLDR) method. ${ }^{18}$ At first, a 226 bp DNA fragment containing the polymorphic site was amplified by PCR. The sequences of primers of rs2279744 were as follows: forward primer: 5'-AGTTCAGGGTAAAGGTCACGG-3'; reverse primer: 5'-GACAAGTCAGGACTTAACTCC-3'. The PCR was carried out in a total volume of $15 \mu \mathrm{L}$ containing $1.5 \mu \mathrm{L}$ $10 \times$ PCR buffer, $1 \mu \mathrm{L}$ genome DNA, $1.5 \mu \mathrm{L} \mathrm{MgCL}_{2}, 0.3$ $\mu \mathrm{L}$ deoxynucleotide, $0.3 \mu \mathrm{L}$ Taq DNA polymerase, $0.15 \mu \mathrm{L}$ each primer, and $10.1 \mu \mathrm{L} \mathrm{H}_{2} \mathrm{O}$. The PCR conditions were $94^{\circ} \mathrm{C}$ for 3 minutes, followed by 35 cycles at $94^{\circ} \mathrm{C}$ for 15 seconds, $55^{\circ} \mathrm{C}$ for 15 seconds, $72^{\circ} \mathrm{C}$ for 30 seconds, with a final extension at $72^{\circ} \mathrm{C}$ for 3 minutes. Then, LDR was performed using the following probes: common probe: -P-CGGCGCGGGAGGTCCGGATGATCGCTTTTTTT TT-FAM-; discriminating probe: T:TTTTTTTTTTTTTTT GGGGCCGGGGGCTGCGGGGCCGCTT; discriminating probe: G:TTTTTTTTTTTTGGGGCCGGGGGCTGCGGG GCCGCTG. LDR was carried out in $10 \mu \mathrm{L}$ reaction mixture

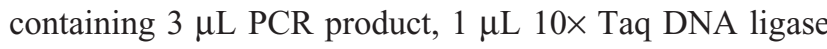
buffer, $0.125 \mu \mathrm{L}$ Taq DNA ligase $(40 \mathrm{U} / \mu \mathrm{L}), 0.01 \mu \mathrm{L}$ of each probe $(10 \mathrm{pmol})$, and $5.845 \mu \mathrm{L} \mathrm{H}_{2} \mathrm{O}$. The LDR conditions were 30 cycles at $94^{\circ} \mathrm{C}$ for 30 seconds and $56^{\circ} \mathrm{C}$ for 3 minutes. At last, LDR products were sequenced using ABI 3730XL genetic analyzer (Applied Biosystems, Foster City, CA, USA) and the results were analyzed with GeneMapper software (Applied Biosystems). Approximately 10\% of the samples were randomly selected and retested by direct DNA sequencing and the results were $100 \%$ concordant. All the genotyping experiments were done with technical support of Shanghai Generay Biotech Co., Ltd.

\section{Identification of eligible studies for meta-analysis}

To explore the association between the MDM2 SNP309 T $>$ G polymorphism and bladder cancer risk in different studies and ethnicities, we conducted a meta-analysis to summarize our findings along with previously published studies. For the meta-analysis, an extensive literature search was performed up to July 20, 2015, using the PubMed and Embase databases to identify relevant studies. Search terms used included: "murine double minute 2" or "MDM 2", "bladder", "cancer" or "carcinoma" or "tumor", "polymorphism" or "variant" or "mutation" or "SNP309" or "T309G" or "rs2279744". The search was limited to English-language papers only. In addition, the reference lists of all included studies were searched for additional references. The studies meeting the following criteria were included in our meta-analysis: 1) studies that evaluated the association between the MDM2 SNP309 T $>$ G polymorphisms and bladder cancer, 2) casecontrol studies, 3) sufficient genotype data were presented to perform meta-analysis. Studies without control subjects and useful data were excluded.

\section{Statistical analysis}

In this study, data were described as mean \pm standard deviation for continuous variables and as numbers and percentages or frequencies for categorical variables. The goodness-of-fit chi-square test was used to analyze any deviation from the Hardy-Weinberg equilibrium in controls. The differences in demographic characteristics between cases and controls were evaluated by two-sided test (for categorical variables) or Student's $t$-test (for continuous variables). Chi-square test was used to compare the differences in the allele and genotype frequencies between bladder cancer patients and the health controls. After adjusting the confounding effect of age, sex, and smoking status, logistic regression was used to calculate odds ratio (OR) and 95\% confidence interval (CI) to analyze the relationship between the genotype and susceptibility of bladder cancer, and the homozygous genotype for the common allele of each SNP was used as the reference in the logistic regression analyses. Survival curves were plotted using the Kaplan-Meier method and **analyzed by the log-rank test to analyze the association between the genotype and risk of recrudesce in NMIBC patients. Hazard ratios (HRs) and 95\% CI using the Cox proportional hazards regression model were calculated to investigate whether MDM2 SNP309 T $>$ G 
polymorphism was independent prognostic factor of bladder cancer. The chi-square-based Q-test was used to test the heterogeneity of effect sizes between subgroups. A two-side $P<0.05$ was considered as statistically significant. All above analyses were performed using SPSS 19.0 software (IBM, Armonk, NY, USA). Meta-analysis and all related statistics were performed by STATA 12.0 (College Station, TX, USA). The strength of the associations between bladder cancer and the MDM2 SNP309 polymorphisms was estimated by ORs and $95 \%$ CIs. Statistical heterogeneity was analyzed using the chi-square test. A value of $P<0.05$ was used to indicate heterogeneity. $I^{2}$ statistic was also computed to test for heterogeneity. $I^{2}$ ranges from $0 \%$ to $100 \%$, and $I^{2}$ values of $25 \%$, $50 \%$, and $75 \%$ were nominally assigned as low, moderate, and high estimates. A fixed-effects model was applied when heterogeneity was not observed, whereas a random-effects model of meta-analysis was used if heterogeneity existed. Additionally, we conducted sensitivity analyses by excluding each study individually and recalculating the ORs and 95\% CI. Both the Egger's linear regression test and funnel plots analysis were used to evaluate Publication bias.

\section{Results}

\section{Characteristics of subjects}

Table 1 shows the demographic details of the study subjects and clinical characteristics of the patients. A total of 535 bladder cancer patients and 649 health controls were

Table I Demographical details of patients with bladder cancer and healthy controls

\begin{tabular}{|c|c|c|c|}
\hline \multirow[t]{2}{*}{ Variables } & \multirow{2}{*}{$\frac{\text { Cases }(n=535)}{n(\%)}$} & \multirow{2}{*}{$\frac{\text { Controls }(\mathrm{n}=649)}{\mathrm{n}(\%)}$} & \multirow[t]{2}{*}{$P$-value } \\
\hline & & & \\
\hline \multicolumn{4}{|l|}{ Sex } \\
\hline Male & $410(76.6)$ & $482(74.3)$ & 0.347 \\
\hline Female & $125(23.4)$ & $167(25.7)$ & \\
\hline \multicolumn{4}{|l|}{ Age (years) } \\
\hline Mean \pm SD & $65.50 \pm 12.144$ & $64.99 \pm 11.041$ & 0.458 \\
\hline$\leq 65$ & $262(49)$ & $323(49.8)$ & 0.758 \\
\hline$>65$ & $273(5 I)$ & $326(50.2)$ & \\
\hline \multicolumn{4}{|l|}{ Smoking status } \\
\hline Never & $293(54.8)$ & 428 (65.9) & $<0.001$ \\
\hline Ever & $242(45.2)$ & $221(34.1)$ & \\
\hline Former smoker & $115(21.5)$ & $89(13.7)$ & \\
\hline Current smoker & $127(23.7)$ & $132(20.3)$ & \\
\hline \multicolumn{4}{|l|}{ Tumor stage } \\
\hline $\operatorname{NMIBC}(\mathrm{Ta} \& \mathrm{TI})$ & $443(82.8)$ & NA & NA \\
\hline $\operatorname{MIBC}(\geq \mathrm{T} 2)$ & $92(17.2)$ & NA & \\
\hline \multicolumn{4}{|l|}{ Tumor grade } \\
\hline Low grade & $211(39.4)$ & NA & NA \\
\hline High grade & $324(60.6)$ & NA & \\
\hline
\end{tabular}

Note: Significant data are emphasized in bold.

Abbreviations: SD, standard deviation; NMIBC, nonmuscle-invasive bladder cancer; MIBC, muscle-invasive bladder cancer; Ta, non-invasive papillary carcinoma; TI, tumour invades subepithelial connective tissue; T2, tumour invades muscle; NA, not applicable. recruited for our study. Mean age of the cases and controls was $65.50 \pm 12.144$ and $64.99 \pm 11.041$ years, respectively. There was no significant difference in sex and age between the cases and controls $(P>0.05)$. However, there were significant differences in the smoking status between the two groups, and the cases had significantly higher percentage of smokers (45.2\%) than the controls $(34.1 \%)(P<0.001)$. Of the 535 total bladder cancer patients enrolled in the study, 443 patients had NMIBC, while the rest 92 had MIBC. A total of 211 patients showed low-grade bladder cancer, which included papillary urothelial neoplasm of low malignant potential patients and the other 324 patients showed high grade in our study.

\section{Association between MDM2 SNP309T>G polymorphism and bladder cancer risk}

The genotype and allele frequencies of MDM2 SNP309 $\mathrm{T}>\mathrm{G}$ polymorphism in controls and cases are presented in Table 2. The genotype frequencies of controls were consistent with Hardy-Weinberg equilibrium $(P>0.05)$. When the TT genotype and $\mathrm{T}$ allele served as reference, we found no significant difference in either genotype or allele frequencies of MDM2 SNP309 T>G polymorphism between bladder cancer patients and health controls (all $P>0.05$ ). Subsequently, a stratification analysis was performed to evaluate the association of MDM2 SNP309 T>G polymorphism with bladder cancer stage or grade (Table 3 ). Compared with TT genotype, we combined TG and GG genotypes as a dominant genetic model in the stratification analysis. As shown in Table 3, $\mathrm{G}$ allele carriers were prone to have a significant decrease in risk of low-grade bladder cancer (adjusted OR: 0.613, 95\% CI: $0.427-0.881, P=0.008)$. In addition to this, no significant association was observed between MDM2 SNP309 $\mathrm{T}>\mathrm{G}$ polymorphism and tumor stage or high-grade bladder cancer (all $P>0.05$ ). Comparing the frequency of MDM2 SNP309 $\mathrm{T}>\mathrm{G}$ polymorphism, significant heterogeneity

Table 2 Genotype and allele frequencies of the MDM2 SNP309 $\mathrm{T}>\mathrm{G}$ polymorphism among cases and controls and their associations with risk of bladder cancer

\begin{tabular}{|c|c|c|c|c|}
\hline \multirow[t]{2}{*}{ Genotypes } & \multirow{2}{*}{$\begin{array}{l}\begin{array}{l}\text { Cases } \\
(n=535)\end{array} \\
n(\%)\end{array}$} & \multirow{2}{*}{$\begin{array}{l}\text { Controls } \\
(n=649) \\
n(\%)\end{array}$} & \multirow[t]{2}{*}{$P$-value } & \multirow[t]{2}{*}{ OR $(95 \% \mathrm{CI})^{*}$} \\
\hline & & & & \\
\hline TT & $126(23.6)$ & $130(20)$ & Ref & Ref \\
\hline TG & $259(48.4)$ & $324(50)$ & 0.160 & $0.807(0.599-1.088)$ \\
\hline GG & $150(28.0)$ & $195(30)$ & 0.141 & $0.783(0.564-1.085)$ \\
\hline $\mathrm{TG}+\mathrm{GG}$ & $409(76.4)$ & $519(80)$ & 0.121 & $0.802(0.606-1.060)$ \\
\hline T allele & $5 I I(47.8)$ & $584(45)$ & Ref & Ref \\
\hline G allele & $559(52.2)$ & $7 \mid 4(55)$ & 0.165 & $0.891(0.756-1.049)$ \\
\hline
\end{tabular}

Note: *Adjusted for age, sex, and smoking status in logistic regression model. Abbreviations: MDM2, human murine double minute 2 protein; OR, odds ratio; $\mathrm{Cl}$, confidence interval; Ref, reference. 
Table 3 Stratification analysis of association between MDM2 SNP309 T $>$ G polymorphism and bladder cancer

\begin{tabular}{|c|c|c|c|c|}
\hline \multirow[t]{2}{*}{ Variables } & \multicolumn{2}{|c|}{ Genotype, n (\%) } & \multirow[t]{2}{*}{$P$-value } & \multirow[t]{2}{*}{ OR $(95 \% \mathrm{CI})^{*}$} \\
\hline & TT & $\mathbf{T G}+\mathbf{G G}$ & & \\
\hline $\begin{array}{l}\text { Controls } \\
(n=649)\end{array}$ & 130 (20) & $519(80)$ & Ref & Ref \\
\hline $\begin{array}{l}\text { Cases } \\
\text { (total } n=535 \text { ) }\end{array}$ & $126(23.6)$ & 409 (76.4) & 0.121 & $0.802(0.606-1.060)$ \\
\hline NMIBC & $105(23.7)$ & $338(76.3)$ & 0.136 & $0.800(0.596-1.073)$ \\
\hline MIBC & $28(22.8)$ & $64(77.2)$ & 0.474 & $0.824(0.486-1.399)$ \\
\hline Low grade & $60(28.4)$ & I5I (7I.6) & 0.008 & $0.613(0.427-0.881)$ \\
\hline High grade & $66(20.4)$ & $258(79.6)$ & 0.911 & $0.98 \mid(0.699-1.376)$ \\
\hline
\end{tabular}

Notes: *Adjusted for age, sex, and smoking status in logistic regression model. Significant data are emphasized in bold.

Abbreviations: MDM2, human murine double minute 2 protein; Ref, reference; $\mathrm{OR}$, odds ratio; $\mathrm{Cl}$, confidence interval; NMIBC, nonmuscle-invasive bladder cancer: MIBC, muscle-invasive bladder cancer.

was observed between low- and high-grade bladder cancer $(P=0.032)$, and there was no heterogeneity between NMIBC and $\operatorname{MIBC}(P=0.174)$.

\section{Association of MDM2 SNP309T >G polymorphism with smoking status in patients with bladder cancer}

In the study, we evaluated the interaction of gene and smoking status to study the modulation of bladder cancer risk with respect to MDM2 SNP309 $\mathrm{T}>\mathrm{G}$ polymorphism. The bladder cancer cases were grouped as nonsmokers and smokers, and Table 4 shows the results. The MDM2 SNP309 T $>$ G polymorphism genotypes and alleles frequency distribution revealed that none of the genotypes and alleles was associated with bladder cancer in individuals with tobacco habits (all $P>0.05$ ).

\section{Association of MDM2 SNP309 $\mathrm{T}>\mathrm{G}$ polymorphism with the risk of recurrence in NMIBC patients}

To analyze the association of MDM2 SNP309 T $>$ G polymorphism and risk of recurrence in NMIBC patients, the

Table 4 Association of MDM2 SNP309 T > G polymorphism with smoking status in patients

\begin{tabular}{|c|c|c|c|c|}
\hline \multirow[t]{2}{*}{ Genotypes } & \multirow{2}{*}{$\begin{array}{l}\text { Smokers } \\
(\mathrm{n}=242) \\
n(\%)\end{array}$} & \multirow{2}{*}{$\begin{array}{l}\text { Nonsmokers } \\
(\mathrm{n}=293) \\
\mathrm{n}(\%)\end{array}$} & \multirow{2}{*}{ P-value } & \multirow[t]{2}{*}{ OR $(95 \% \mathrm{Cl})^{*}$} \\
\hline & & & & \\
\hline TT & 70 (28.9) & $92(31.4)$ & Ref & Ref \\
\hline TG & $108(44.6)$ & $143(48.8)$ & 0.838 & $0.956(0.622-1.470)$ \\
\hline GG & $64(26.4)$ & $58(19.8)$ & 0.625 & I.I38 (0.678-1.909) \\
\hline $\mathrm{TG}+\mathrm{GG}$ & $172(7 \mid . I)$ & $201(68.6)$ & 0.947 & $1.014(0.677-1.519)$ \\
\hline T allele & $248(5 \mid .2)$ & $327(55.8)$ & Ref & Ref \\
\hline G allele & $236(48.8)$ & $259(44.2)$ & 0.555 & $1.082(0.833-1.406)$ \\
\hline
\end{tabular}

Note: *Adjusted for age and sex in logistic regression model.

Abbreviations: MDM2, human murine double minute 2 protein; OR, odds ratio; $\mathrm{Cl}$, confidence interval; Ref, reference.
Kaplan-Meier survival curve was conducted in NMIBC patients only. Recurrence-free survival was defined as the interval from surgery to the first relapse. The mean follow-up was $14.38 \pm 6.48$ months (3-24 months). Of the 443 NMIBC patients, 81 patients had a recurrence in durations of follow-up. As shown in Figure 1, patients with G allele had a markedly longer recurrence-free survival than those with TT genotype $(P<0.05)$. The results of multivariable Cox proportional hazards regression model showed that both the TG (adjusted HR: $0.562,95 \%$ CI: $0.338-0.933$, $P=0.026$ ) and GG genotype (adjusted HR: $0.501,95 \% \mathrm{CI}$ : $0.279-0.900, P=0.021)$ were associated with decreasing the risk of recurrence in NMIBC patients (Table 5). Similarly, significant associations were also found in the dominant model TG + GG versus TT (adjusted HR: 0.531, 95\% CI: $0.336-0.839, P=0.007)$.

Subsequently, we analyzed the association of MDM2 SNP309 T $>$ G polymorphism and risk of recurrence in NMIBC patients with cisplatin-based combination chemotherapy $(\mathrm{n}=126)$. The mean follow-up was $13.60 \pm 5.60$ months (3-24 months). The results showed significant association between MDM2 SNP309 T $>$ G polymorphism and risk of recurrence in NMIBC patients treated with cisplatin-based combination chemotherapy (Figure 2, Table 6). Compared with TT genotype, $G$ allele carriers were prone to have a significant decrease in risk of recurrence (adjusted HR: $0.506,95 \%$ CI: $0.275-0.931, P=0.029$ for TG vs TT; adjusted HR: 0.275 , 95\% CI: $0.116-0.654, P=0.004$ for GG vs TT; adjusted HR: $0.397,95 \%$ CI: $0.224-0.703, P=0.002$ for TG + GG vs TT).

\section{Meta-analysis}

The search strategy yielded a total of 87 articles. After removing 29 duplicates, we screened 58 potentially relevant articles. Finally, a total of six studies (five previous studies and the present study) with 1,507 cases and 1,661 health controls were included in our meta-analysis. ${ }^{19-23}$ The excluded studies and reasons are shown in Figure 3. All included studies were published in English. Of the six studies, five studies assessed Caucasian populations, whereas the others assessed Asian populations. The main characteristics of the studies included in our meta-analysis are listed in Table 7. The distribution of genotypes in the controls was consistent with HardyWeinberg equilibrium in all studies $(P>0.05)$.

The pooled results of the meta-analysis are shown in Table 8 . We first analyzed the association in the overall population and the combined results indicated that MDM2 SNP309 $\mathrm{T}>\mathrm{G}$ polymorphism was not significantly associated with bladder cancer risk in all genetic models (adjusted 

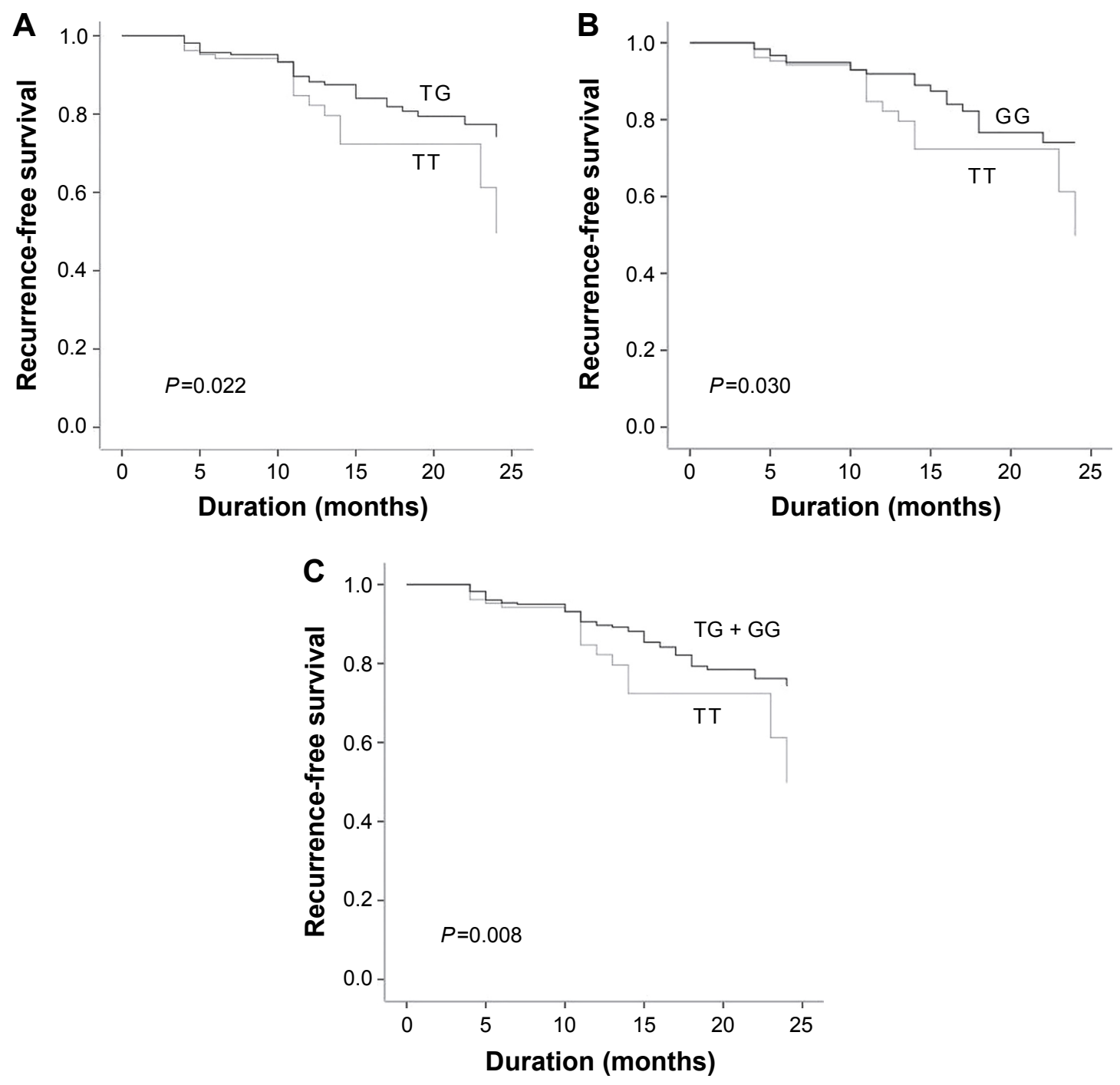

Figure I Kaplan-Meier curve for influence of MDM2 SNP309 T>G polymorphism on risk of recurrence in NMIBC patients. Notes: (A) The TG versus TT genotype contrast; (B) the GG versus TT genotype contrast; and (C) the TG + GG versus TT genotype contrast. Abbreviations: MDM2, human murine double minute 2 protein; NMIBC, nonmuscle-invasive bladder cancer.

OR: $1.028,95 \%$ CI: $0.856-1.234, P=0.769$ for $\mathrm{T}$ allele vs G allele; adjusted OR: $0.898,95 \%$ CI: $0.755-1.069, P=0.227$ for TG vs TT; adjusted OR: $1.079,95 \%$ CI: $0.742-1.569$, $P=0.689$ for GG vs TT; adjusted OR: $0.918,95 \% \mathrm{CI}$ : $0.779-1.080, P=0.302$ for TG + GG vs TT, Figure 4). For an optimal consistency of the results, stratified analyses were performed by ethnicity. Subgroup analyses showed that there was also no significant association of MDM2 SNP309 T $>\mathrm{G}$ polymorphism with risk of bladder cancer in Asians (all $P>0.05$, Table 8). However, compared with wild T allele, the variant $\mathrm{G}$ allele has significant association with the risk of bladder cancer in Caucasian populations (adjusted OR:

Table 5 Multivariate analyses of MDM2 SNP309 T>G polymorphism in NMIBC patients with respect to RFS

\begin{tabular}{|c|c|c|c|c|}
\hline \multirow[t]{2}{*}{ Genotypes } & \multirow{2}{*}{$\begin{array}{l}\text { Recurrence }(\mathrm{n}=8 \mathrm{I}) \\
\mathrm{n}(\%)\end{array}$} & \multirow{2}{*}{$\frac{\text { No recurrence }(n=362)}{n(\%)}$} & \multirow[t]{2}{*}{$P$-value } & \multirow[t]{2}{*}{ HR $(95 \% \mathrm{CI})^{*}$} \\
\hline & & & & \\
\hline TT & $30(37.0)$ & $75(20.7)$ & Ref & Ref \\
\hline TG & $32(39.5)$ & $184(50.8)$ & 0.026 & $0.562(0.338-0.933)$ \\
\hline GG & $19(23.5)$ & $103(28.5)$ & 0.021 & $0.50 I(0.279-0.900)$ \\
\hline $\mathrm{TG}+\mathrm{GG}$ & $51(63)$ & $287(79.3)$ & 0.007 & 0.53 I (0.336-0.839) \\
\hline
\end{tabular}

Notes: *Adjusted for age, sex, and smoking status in logistic regression model. Significant data are emphasized in bold.

Abbreviations: RFS, recurrence-free survival; MDM2, human murine double minute 2 protein; HR, hazard ratios; $\mathrm{Cl}$, confidence interval; $\mathrm{NMIBC}$, nonmuscle-invasive bladder cancer; Ref, reference. 

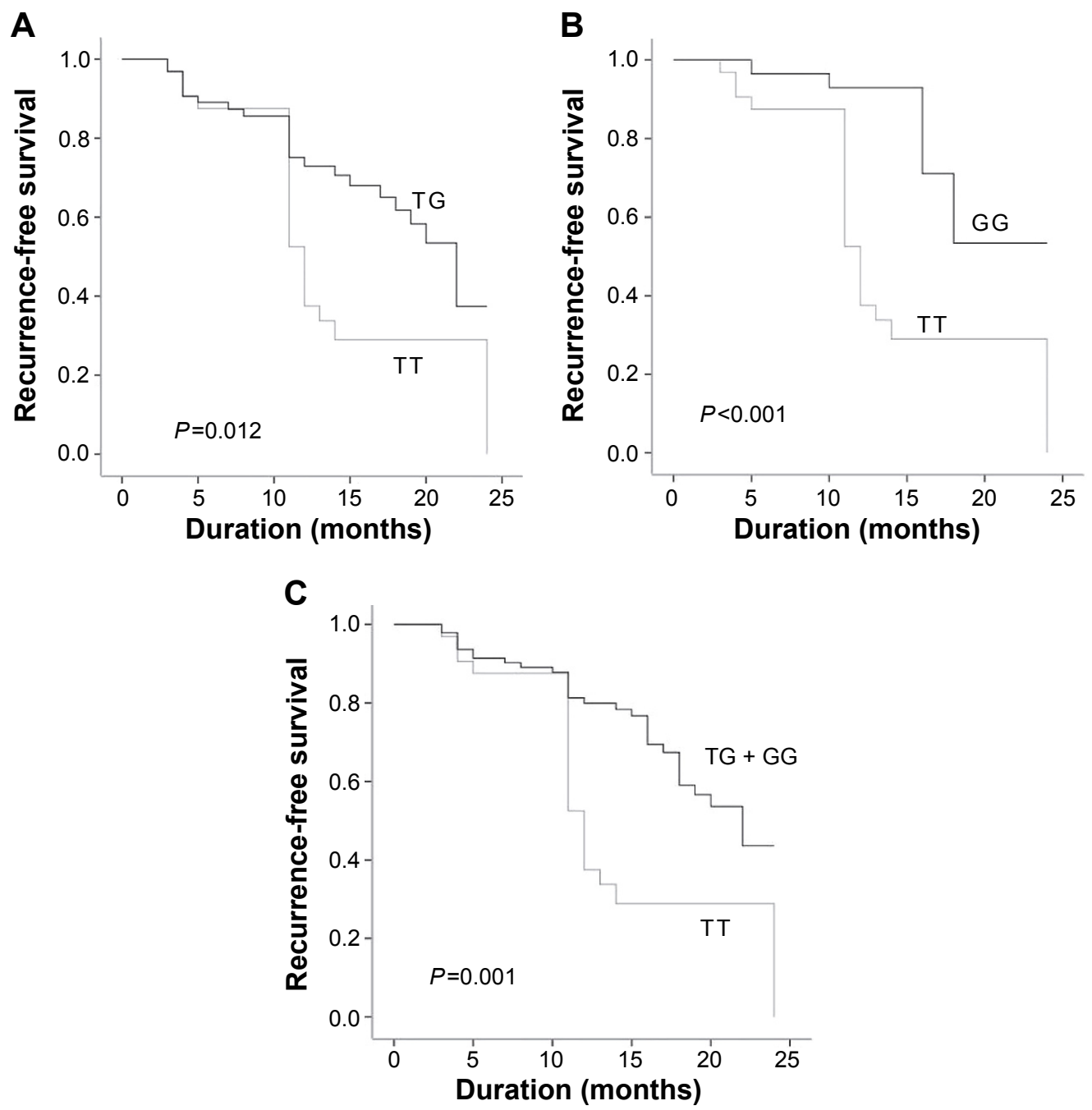

Figure 2 Kaplan-Meier curve for influence of MDM2 SNP309 T>G polymorphism on risk of recurrence in NMIBC patients treated with cisplatin-based combination chemotherapy.

Notes: (A) The TG versus TT genotype contrast; (B) the GG versus TT genotype contrast; and (C) the TG + GG versus TT genotype contrast.

Abbreviations: MDM2, human murine double minute 2 protein; NMIBC, nonmuscle-invasive bladder cancer.

1.450, 95\% CI: $1.024-2.055, P=0.036)$. Similarly, GG genotype also showed increased risk of bladder cancer as compared with the wild-type homozygous TT genotype in Caucasians (adjusted OR: 2.247, 95\% CI: 1.166-4.332, $P=0.016$ ). In both comparisons of TG versus TT and TG
+ GG versus TT, no significant statistical differences were observed in Caucasians (both $P>0.05$, Table 8). Egger's test and funnel plots were used to evaluate publication bias, and no significant publication biases were observed in our meta-analysis.

Table 6 Multivariate analyses of MDM2 SNP309 T>G polymorphism on the risk of recurrence of NMIBC patients treated with cisplatin-based combination chemotherapy

\begin{tabular}{|c|c|c|c|c|}
\hline \multirow[t]{2}{*}{ Genotypes } & \multirow{2}{*}{$\frac{\text { Recurrence }(n=54)}{n(\%)}$} & \multirow{2}{*}{$\frac{\text { No recurrence }(n=72)}{n(\%)}$} & \multirow[t]{2}{*}{$P$-value } & \multirow[t]{2}{*}{ HR (95\% Cl)* } \\
\hline & & & & \\
\hline TT & $21(38.9)$ & II (I5.3) & Ref & Ref \\
\hline TG & $24(44.4)$ & $40(55.6)$ & 0.029 & $0.506(0.275-0.93 I)$ \\
\hline GG & $9(16.7)$ & $21(29.2)$ & 0.004 & $0.275(0.116-0.654)$ \\
\hline$T G+G G$ & $5 I(6||)$. & $61(84.7)$ & 0.002 & $0.397(0.224-0.703)$ \\
\hline
\end{tabular}

Notes: *Adjusted for age, sex, and smoking status in logistic regression model. Significant data are emphasized in bold.

Abbreviations: MDM2, human murine double minute 2 protein; NMIBC, nonmuscle-invasive bladder cancer; $\mathrm{HR}$, hazard ratios; Cl, confidence interval; Ref, reference. 


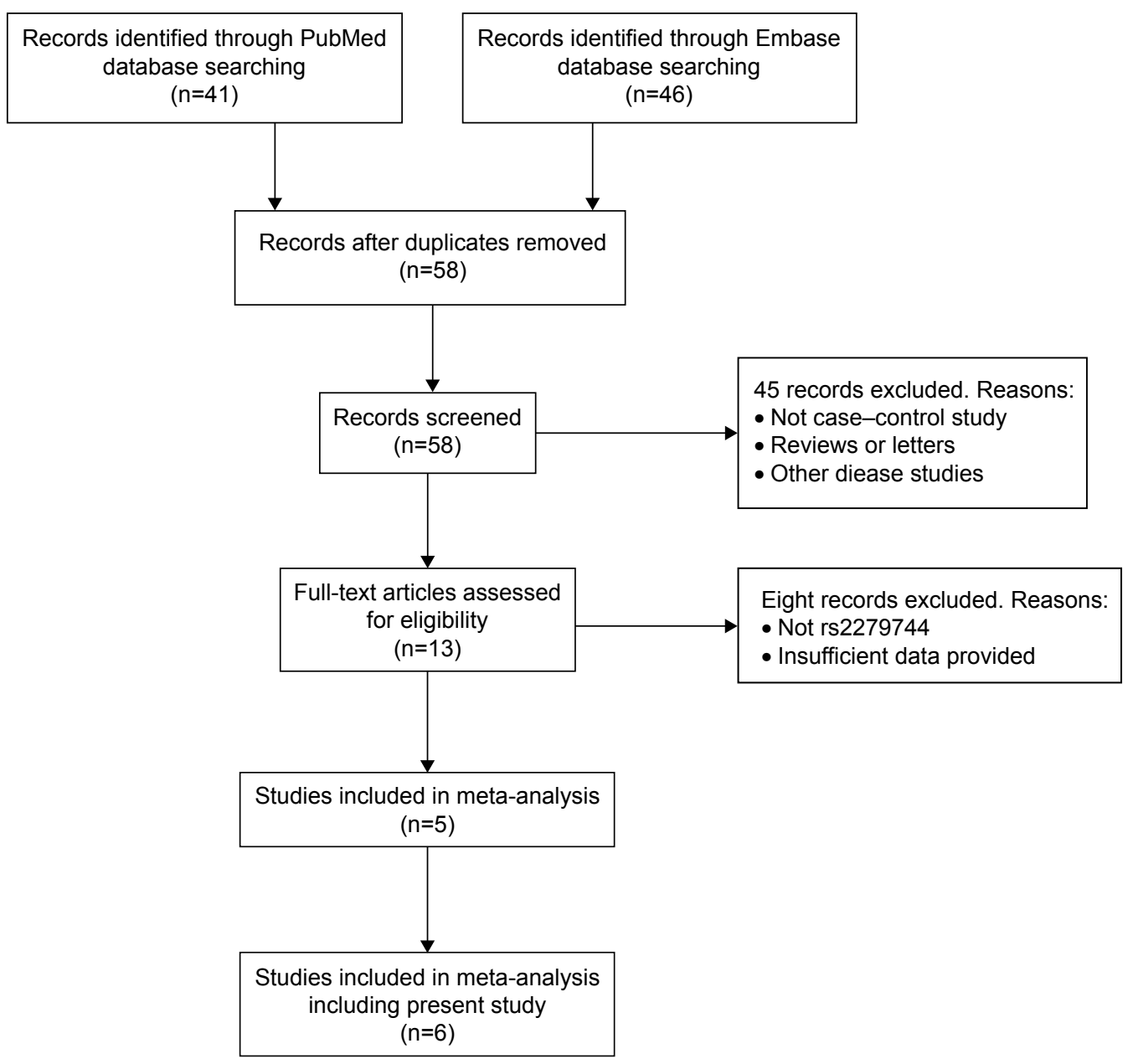

Figure 3 Preferred reporting items for systematic reviews and meta-analysis flowchart.

\section{Discussion}

As we all know, p53 tumor suppressor pathway plays an important role in the prevention of tumor formation, and MDM2 is mainly a negative regulator of $\mathrm{p} 53$. The overexpression of MDM 2 can decrease the level of $\mathrm{p} 53$ protein and eventually results in the dysfunction of the p53 pathway. ${ }^{10}$ Bond et $\mathrm{al}^{10}$ reported that the G allele of MDM2 SNP309
$\mathrm{T}>\mathrm{G}$ polymorphism confers an increased binding affinity to the Sp1 transcriptional activator, which can increase transcription of the MDM2 gene. Therefore, in theory, MDM2 SNP309 $\mathrm{T}>\mathrm{G}$ polymorphism is associated with tumor formation and adverse clinical behaviors of tumors, such as fast progression and poor treatment response. ${ }^{24}$ Actually, some studies indeed found that G allele of MDM2

Table 7 Main characteristics of studies included in this meta-analysis

\begin{tabular}{|c|c|c|c|c|c|c|c|c|c|}
\hline Study & $\begin{array}{l}\text { Year } \\
\text { published }\end{array}$ & Country & Ethnicity & $\begin{array}{l}\text { Genotyping } \\
\text { methods }\end{array}$ & $\begin{array}{l}\text { Cases } \\
\text { (n) }\end{array}$ & $\begin{array}{l}\text { Controls } \\
\text { (n) }\end{array}$ & $\begin{array}{l}\text { Cases: } \\
\text { TT/TG/GG }\end{array}$ & $\begin{array}{l}\text { Controls: } \\
\text { TT/TG/GG }\end{array}$ & HWE \\
\hline Onat et al ${ }^{19}$ & 2006 & Turkey & Caucasian & PCR-RFLP & 75 & 103 & $13 / 36 / 26$ & $29 / 57 / 17$ & 0.216 \\
\hline Wang et $\mathrm{a}^{20}$ & 2008 & $\begin{array}{l}\text { People's Republic } \\
\text { of China }\end{array}$ & Asian & PCR-RFLP & 234 & 253 & $62 /|2| / 5 \mid$ & $64 / 134 / 55$ & 0.335 \\
\hline Horikawa et $\mathrm{al}^{21}$ & 2008 & Japan & Asian & TaqMan & 227 & 266 & $44 / 116 / 67$ & $55 / 132 / 79$ & 0.992 \\
\hline Gangwar and Mittal ${ }^{22}$ & 2010 & India & Asian & PCR-RFLP & 212 & 250 & $70 / 89 / 53$ & $62 / 113 / 75$ & 0.139 \\
\hline Hitzenbichler et $\mathrm{al}^{23}$ & 2014 & Germany & Caucasian & PCR-RFLP & 224 & 140 & $75 / 101 / 48$ & $51 / 70 / 19$ & 0.514 \\
\hline Present study & 2015 & $\begin{array}{l}\text { People's Republic } \\
\text { of China }\end{array}$ & Asian & PCR-LDR & 535 & 649 & $126 / 259 / 150$ & $130 / 324 / 195$ & 0.827 \\
\hline
\end{tabular}

Abbreviations: PCR-LDR, polymerase chain reaction-ligation detection reaction; PCR-RFLP, polymerase chain reaction-restriction fragment length polymorphism; HWE, Hardy-Weinberg equilibrium. 
Table 8 Meta-analysis of MDM2 SNP309 T>G polymorphism and bladder cancer risk

\begin{tabular}{|c|c|c|c|c|c|}
\hline \multirow[t]{2}{*}{ Allele and genotype } & \multirow[t]{2}{*}{ Populations } & \multicolumn{2}{|c|}{ Heterogeneity } & \multirow[t]{2}{*}{$P$-value } & \multirow[t]{2}{*}{ OR $(95 \% \mathrm{Cl})$} \\
\hline & & $P$-value & $I^{2}(\%)$ & & \\
\hline \multirow[t]{3}{*}{ G allele vs $T$ allele } & All populations & 0.011 & 66.5 & 0.769 & $1.028(0.856-1.234)$ \\
\hline & Caucasians & 0.176 & 45.3 & 0.036 & $1.450(1.024-2.055)$ \\
\hline & Asians & 0.418 & 0 & 0.082 & $0.908(0.814-1.012)$ \\
\hline \multirow[t]{3}{*}{ TG vs TT } & All populations & 0.585 & 0 & 0.227 & $0.898(0.755-1.069)$ \\
\hline & Caucasians & 0.434 & 0 & 0.697 & I.082 (0.726-I.6I4) \\
\hline & Asians & 0.546 & 0 & 0.126 & $0.860(0.709-1.043)$ \\
\hline \multirow[t]{3}{*}{ GG vs TT } & All populations & 0.009 & 67.3 & 0.689 & I.079 (0.742-I.569) \\
\hline & Caucasians & 0.222 & 33.1 & 0.016 & $2.247(1.166-4.332)$ \\
\hline & Asians & 0.474 & 0 & 0.082 & $0.825(0.664-1.025)$ \\
\hline \multirow[t]{3}{*}{ TG + GG vs TT } & All populations & 0.150 & 38.5 & 0.302 & $0.918(0.779-1.080)$ \\
\hline & Caucasians & 0.258 & 21.9 & 0.166 & $1.305(0.896-1.900)$ \\
\hline & Asians & 0.419 & 0 & 0.069 & $0.845(0.705-1.013)$ \\
\hline
\end{tabular}

Note: Significant data are emphasized in bold.

Abbreviations: MDM2, human murine double minute 2 protein; $\mathrm{OR}$, odds ratio; $\mathrm{Cl}$, confidence interval.

SNP309 $\mathrm{T}>\mathrm{G}$ polymorphism was associated with increased risk of some tumor, such as leukemia, gastric cancer, hepatocellular cancer, and colorectal cancer. ${ }^{25-28}$ However, inverted results were observed in some other tumors, for example, head and neck cancer and prostate cancer ${ }^{29,30}$ and studies suggested that variant $\mathrm{G}$ allele may play a preventive role in these tumors. Therefore, MDM2 SNP309 T $>$ G polymorphism might play different roles in the genesis of different cancers. The difference might be influenced by different sample size and different genetic background.

As for the association of MDM2 SNP309 T>G polymorphism and bladder cancer risk, conflicting results were observed in previously published studies. Studies by Wang et $\mathrm{al},{ }^{20}$ Horikawa et $\mathrm{al},{ }^{21}$ and Hitzenbichler et $\mathrm{al}^{23}$ showed no significant association between the MDM2 SNP309 $\mathrm{T}>\mathrm{G}$ polymorphism and bladder cancer risk. Gangwar and Mittal $^{22}$ suggested that MDM2 SNP309 T $>$ G polymorphism may decrease the risk of breast cancer, ${ }^{22}$ whereas Onat et al ${ }^{19}$ indicated that MDM2 polymorphisms have some effect on increasing risk of bladder cancer. In our study based on 535 cases and 649 controls, no significant association was observed between MDM2 SNP309 T $>$ G polymorphism and bladder cancer risk. However, in the stratification analysis between the MDM2 SNP309 $\mathrm{T}>\mathrm{G}$ polymorphism and bladder cancer status (stage and grade), we found that $\mathrm{G}$ allele carriers were prone to have a significant decrease in risk of low-grade bladder cancer. This result implied that the $\mathrm{G}$ allele might be associated with a protective phenotype. In our study, we also evaluated the gene-smoking interaction to study the modulation of bladder cancer risk with respect to MDM2 SNP309 $\mathrm{T}>\mathrm{G}$ polymorphism, and no significant association was observed in the case of MDM2 SNP309 $\mathrm{T}>\mathrm{G}$ polymorphism with the risk for bladder cancer with smoking.
Previous study has suggested MDM2 gene polymorphism as an important determinant in the risk of recurrence in cancers. ${ }^{31}$ Yurakh et $\mathrm{l}^{32}$ suggested that high expression of MDM2 in bladder cancers was shown to be associated with a better progression-free and a better overall survival of the patients. In our study, we evaluated the influence of MDM2 SNP309 $T>G$ polymorphism on the risk of recurrence of NMIBC patients, and the results showed that the NMIBC patients with $\mathrm{G}$ allele of MDM2 SNP309 $\mathrm{T}>\mathrm{G}$ polymorphism had significant reduced risk of recurrence. For the NMIBC patients treated with cisplatin-based combination chemotherapy, $\mathrm{G}$ allele carriers also showed significant reduced risk of recurrence. These results were inconsistent with the findings of Horikawa et al. ${ }^{21}$ However, consistent results with ours were observed in the study by Shinohara et al. ${ }^{33}$ Gangwar and $\mathrm{Mittal}^{22}$ also found that MDM2 SNP309 GG variant genotype was associated with reduced risk of recurrence in NMIBC patients receiving BCG treatment. ${ }^{22}$ These results suggested that $\mathrm{G}$ allele might be associated with better clinical outcome in NMIBC patients with or without drug treatment, and it was independent favorable prognostic factor of bladder cancer.

To explore more precisely association between MDM2 SNP309 $\mathrm{T}>\mathrm{G}$ polymorphism and the risk of bladder cancer, an updated meta-analysis with more extensive data was performed in our study. Our meta-analysis results based on five previous studies and present study further supported our results, which showed no significant association between MDM2 SNP309 T $>$ G polymorphism and the susceptibility to bladder cancer in all populations and Asians. However, $\mathrm{G}$ allele and GG genotype showed significant association with increased risk of bladder cancer in Caucasians. These results were consistent with the findings of previous meta-analysis conducted by Wang et al. ${ }^{34}$ 


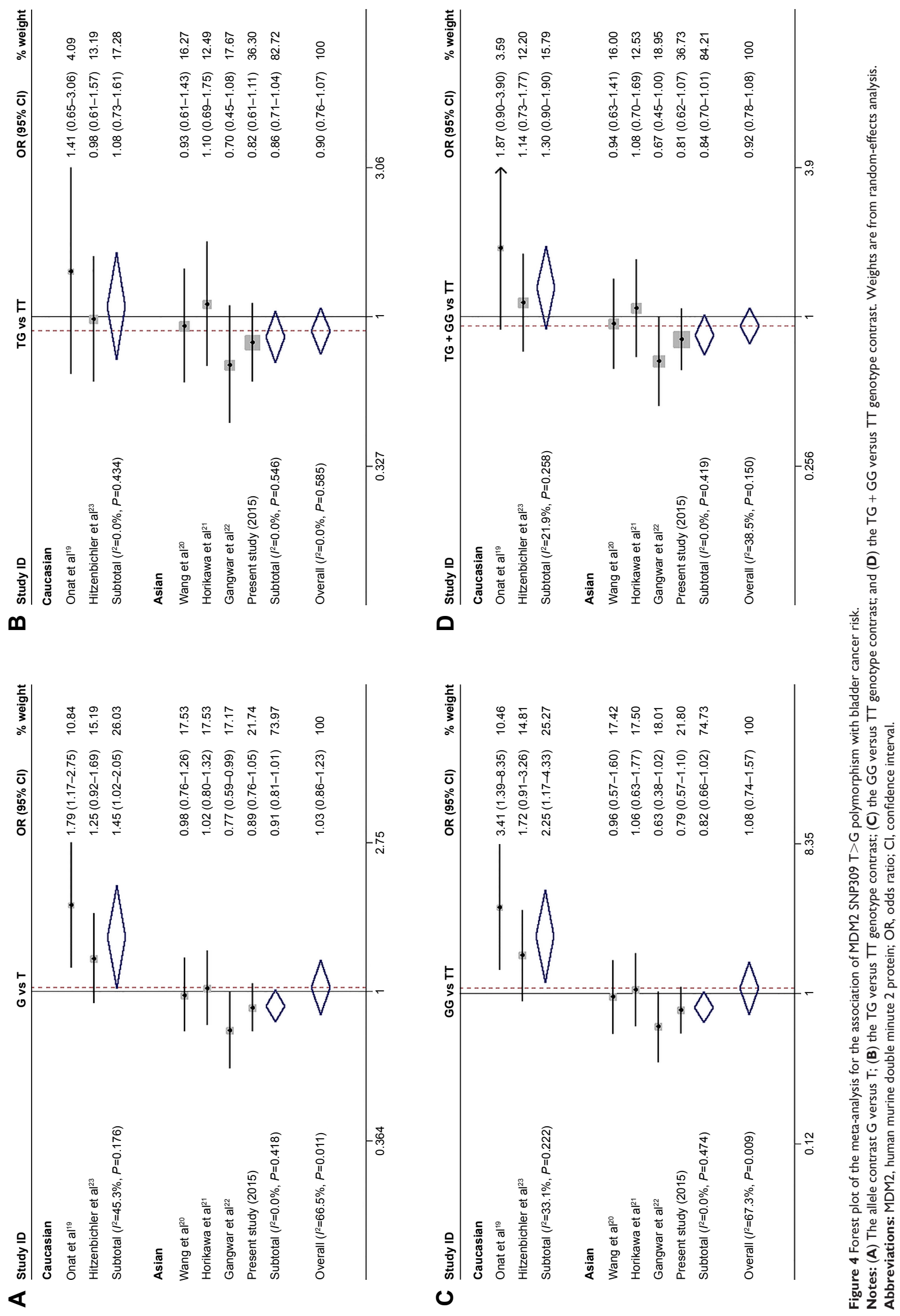


There are some limitations of our study. First, the follow-up durations were too short to obtain a convincing conclusion about recurrence, so these results should be applied carefully in clinical practice. We will keep following these cases in the future to get exact results. Second, although the ethnicity contributed to the potential heterogeneity, heterogeneity was also existent for the association between MDM2 SNP309 T $>$ G polymorphism and bladder cancer risk. Finally, in the subgroup analysis of meta-analysis, there were only two studies on Caucasians and it might result in the false-positive findings. Therefore, the positive results of the Caucasians should be interpreted with caution. Studies with large sample sizes and good designs are needed to confirm the association result between MDM2 SNP309 T $>$ G polymorphism and bladder cancer susceptibility.

\section{Conclusion}

Our study showed that the MDM2 SNP309 T $>$ G polymorphism has no influence on bladder cancer risk in Asians, but this SNP may be associated with genetic susceptibility of bladder cancer among Caucasians. Our result showed that the $G$ allele of the SNP might be associated with decreased risk of recurrence of NMIBC patients, however, the conclusion was unimpressive because of short-time follow-up duration, and we will keep following these cases in the future to get a convincing conclusion.

\section{Acknowledgments}

This project was supported by grants from the National Natural Science Foundation of China (number 30700834), the Natural Science Foundation of Tianjin (number 12ZCDZSY16600), the Natural Science Foundation of Tianjin (number 14JCYBJC26300), the Natural Science Foundation of Tianjin (number 15JCYBJC24600), and the National Key Specialty Construction of Clinical Projects.

\section{Disclosure}

The authors report no conflicts of interest in this work.

\section{References}

1. Ferlay J, Soerjomataram I, Ervik M, et al. GLOBOCAN 2012 v1.2, Cancer Incidence and Mortality Worldwide: IARC Cancer Base No. 11; 2014. Available from: http://globocan.iarc.fr. Accessed June 17, 2015.

2. Torre LA, Bray F, Siegel RL, Ferlay J, Lortet-Tieulent J, Jemal A. Global cancer statistics, 2012. CA Cancer J Clin. 2015;65(2):87-108.

3. Ferlay J, Shin HR, Bray F, Forman D, Mathers C, Parkin DM. Estimates of worldwide burden of cancer in 2008: GLOBOCAN 2008. Int J Cancer. 2010;127(12):2893-2917.

4. Ploeg M, Aben KK, Hulsbergen-van de Kaa CA, Schoenberg MP, Witjes JA, Kiemeney LA. Clinical epidemiology of nonurothelial bladder cancer: analysis of the Netherlands Cancer Registry. J Urol. 2010;183(3): 915-920.
5. Corral R, Lewinger JP, Van Den Berg D, et al. Comprehensive analyses of DNA repair pathways, smoking and bladder cancer risk in Los Angeles and Shanghai. Int J Cancer. 2014;135(2):335-347.

6. Gandini S, Botteri E, Iodice S, et al. Tobacco smoking and cancer: a meta-analysis. Int J Cancer. 2008;122(1):155-164.

7. Burger M, Catto JW, Dalbagni G, et al. Epidemiology and risk factors of urothelial bladder cancer. Eur Urol. 2013;63(2):234-241.

8. Murta-Nascimento C, Silverman DT, Kogevinas M, et al. Risk of bladder cancer associated with family history of cancer: do low-penetrance polymorphisms account for the increase in risk? Cancer Epidemiol Biomarkers Prev. 2007;16(8):1595-1600.

9. Kantor AF, Hartge P, Hoover RN, Fraumeni JF Jr. Familial and environmental interactions in bladder cancer risk. Int J Cancer. 1985;35(6): 703-706.

10. Bond GL, Hu W, Bond EE, et al. A single nucleotide polymorphism in the MDM2 promoter attenuates the p53 tumor suppressor pathway and accelerates tumor formation in humans. Cell. 2004;119(5):591-602.

11. Olivier M, Hussain SP, Caron de Fromentel C, Hainaut P, Harris CC. TP53 mutation spectra and load: a tool for generating hypotheses on the etiology of cancer. IARC Sci Publ. 2004;(157):247-270.

12. Lain $S$, Lane D. Improving cancer therapy by non-genotoxic activation of p53. Eur J Cancer. 2003;39(8):1053-1060.

13. Michael D, Oren M. The p53-Mdm 2 module and the ubiquitin system. Semin Cancer Biol. 2003;13(1):49-58.

14. Iwakuma T, Lozano G. MDM2, an introduction. Mol Cancer Res. 2003; 1(14):993-1000.

15. Bond GL, Levine AJ. A single nucleotide polymorphism in the p53 pathway interacts with gender, environmental stresses and tumor genetics to influence cancer in humans. Oncogene. 2007;26(9):1317-1323.

16. Schoenborn CA, Adams PF, Peregoy JA. Health behaviors of adults: United States, 2008-2010. Vital Health Stat. 2013;(257):1-184.

17. Zhang Y, Sun Y, Chen T, et al. Genetic variations rs11892031 and rs401681 are associated with bladder cancer risk in a Chinese population. Int J Mol Sci. 2014;15(11):19330-19341.

18. Xiao Z, Xiao J, Jiang Y, et al. A novel method based on ligase detection reaction for low abundant YIDD mutants detection in hepatitis B virus. Hepatol Res. 2006;34(3):150-155.

19. Onat OE, Tez M, Ozcelik T, Törüner GA. MDM2 T309G polymorphism is associated with bladder cancer. Anticancer Res. 2006;26(5A): 3473-3475.

20. Wang $\mathrm{M}$, Zhang $\mathrm{Z}$, Zhu $\mathrm{H}$, et al. A novel functional polymorphism $\mathrm{C} 1797 \mathrm{G}$ in the MDM2 promoter is associated with risk of bladder cancer in a Chinese population. Clin Cancer Res. 2008;14(11):3633-3640.

21. Horikawa Y, Nadaoka J, Saito M, et al. Clinical implications of the MDM2 SNP309 and p53 Arg72Pro polymorphisms in transitional cell carcinoma of the bladder. Oncol Rep. 2008;20(1):49-55.

22. Gangwar R, Mittal RD. Association of selected variants in genes involved in cell cycle and apoptosis with bladder cancer risk in North Indian population. DNA Cell Biol. 2010;29(7):349-356.

23. Hitzenbichler F, Stoehr CG, Rogenhofer M, et al. Mdm2 SNP309 G-variant is associated with invasive growth of human urinary bladder cancer. Pathobiology. 2014;81(2):53-59.

24. Freedman DA, Levine AJ. Regulation of the $\mathrm{p} 53$ protein by the MDM2 oncoprotein - thirty-eighth G.H.A. Clowes Memorial Award Lecture. Cancer Res. 1999;59(1):1-7.

25. Qin X, Peng Q, Tang W, et al. An updated meta-analysis on the association of MDM2 SNP309 polymorphism with colorectal cancer risk. PLoS One. 2013;8(9):e76031.

26. Kuang Y, An S, Guo Y, et al. T7 peptide-functionalized nanoparticles utilizing RNA interference for glioma dual targeting. Int J Pharm. 2013; 454(1):11-20.

27. Zhuo W, Zhang L, Ling J, Zhu B, Chen Z. MDM2 SNP309 variation contributes to leukemia risk: meta-analyses based on 7259 subjects. Leuk Lymphoma. 2012;53(11):2245-2252.

28. Lv J, Zhu B, Zhang L, Xie Q, Zhuo W. MDM2 SNP309 variation confers the susceptibility to hepatocellular cancer: a meta-analysis based on 4271 subjects. Int J Clin Exp Med. 2015;8(4):5822-5830. 
29. Liu J, Zheng Y, Lei D, et al. MDM2 309T $>$ G polymorphism and risk of squamous cell carcinomas of head and neck: a meta-analysis. Asian Pac J Cancer Prev. 2011;12(8):1899-1903.

30. Liu G, Jiang D, Shen S, Yu L. Murine double minute 2 promoter SNP309 polymorphism and prostate cancer risk: a meta-analysis. Int $J$ Urol. 2012;19(10):914-920.

31. Hirata H, Hinoda Y, Kikuno N, et al. MDM2 SNP309 polymorphism as risk factor for susceptibility and poor prognosis in renal cell carcinoma. Clin Cancer Res. 2007;13(14):4123-4129.

32. Yurakh AO, Ramos D, Calabuig-Farinas S, et al. Molecular and immunohistochemical analysis of the prognostic value of cell-cycle regulators in urothelial neoplasms of the bladder. Eur Urol. 2006;50(3): $506-515,515$.
33. Shinohara A, Sakano S, Hinoda Y, et al. Association of TP53 and MDM2 polymorphisms with survival in bladder cancer patients treated with chemoradiotherapy. Cancer Sci. 2009;100(12):2376-2382.

34. Wang HG, Wu QY, Zhou H, et al. The MDM2 SNP309T $>$ G polymorphism increases bladder cancer risk among Caucasians: a meta-analysis. Asian Pac J Cancer Prev. 2014;15(13):5277-5281.

\section{Publish your work in this journal}

OncoTargets and Therapy is an international, peer-reviewed, open access journal focusing on the pathological basis of all cancers, potential targets for therapy and treatment protocols employed to improve the management of cancer patients. The journal also focuses on the impact of management programs and new therapeutic agents and protocols on

\section{Dovepress}

patient perspectives such as quality of life, adherence and satisfaction. The manuscript management system is completely online and includes a very quick and fair peer-review system, which is all easy to use. Visit http://www.dovepress.com/testimonials.php to read real quotes from published authors. 